Faculdade de Ciências Econômicas UFRGS
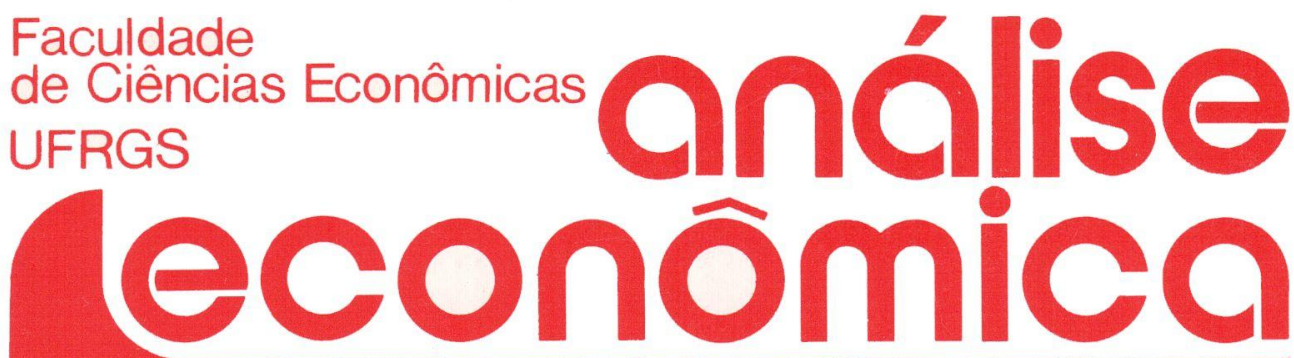

- A LINEAR MOdEL Of BALANCEd GROWTH Joanilio Rodolpho Teixeira Rodrigo Andrés de Souza Penaloza

- TEORIAS ESTRUTURALISTAS DA INFLAÇÃO

Roberto Camps Moraes

- PREÇOS EXTERNOS E EXPÓRTAÇÃO DE MANUFATURADOS Lauro Lobo Burle

- O DESENVOLVIMENTO SUECO Alfredo Marcolin Peringer

- DÉFICIT ENERGÉTICO Fabiano Augusto Nogueira Pinto

- RICARDO E O PROBLEMA SOCIAL Cezar Machado Mello

- UM SABER QUE NÃo SABE: INSTRUMENTO DE PREVISÃO Eleutério F.S. Prado

- SELEÇÃo dE PLANOS DE PRODUÇÃO PARA PEQUENOS PRODUTORES AGRICOLAS Juvir Luiz Mattuella

- PERSPECTIVAS da ECONOMIA do NORDESTE NA DÉCADA DE NOVENTA

Liana Maria da Frota Carleial

- CAIO PRADO JÚNIOR

Pedro Cezar Dutra Fonseca 
UNIVERSIDADE FEDERAL DO RIO GRANDE DO SUL Reitor. Prof. Tuiskon Dick

FACULDADE DE CIÊNCIAS ECONÔMICAS

Diretor: Prof. Walter Meucci Nique

CENTRO DE ESTUDOS E PESQUISAS ECONÔMICAS

Diretor: Reinaldo lgnácio Adams

DEPARTAMENTO DE CIÉNCIAS ECONÔMICAS

Chefe: Prof. Pedro Cezar Dutra Fonseca

CURSO DE PÓS-GRADUAÇÃO EM ECONOMIA

Coordenador: Prof. Nali de Jesus de Souza

CURSO DE PÓS-GRADUAÇĀO EM ECONOMIA RURAL

Coordenador. Prof. Atos Freitas Grawunder

CONSELHO EDITORIAL: Achyles Barcelos da Costa, Aray Miguel Feldens, Atos Freitas Grawunder, Carlos Augusto Crusius, Ernani Hickmann, João Rogério Sanson, Juvir Luiz Mattuella, Maria Imilda da Costa e Silva, Nali de Jesus de Souza, Nuno Renan Lopes de Figueiredo Pinto, Otília Beatriz Kroeff Carrion, Otto Guilherme Konzen, Paulo Alexandre Spohr, Pedro Cezar Dutra Fonseca, Reinaldo Ignacio Adams, Roberto Camps Moraes, Valter José Stülp, Yeda Rorato Crusius, David Garlow (Wharton Econometrics Forecasts Association, E.U.A.), Edgar Augusto Lanzer (UFSC), Eleutério F.S. Prado (USP), Fernando Holanda Barbosa (FGV/RJ), Gustavo Franco (PUC/RJ), Joaquim Pinto de Andrade (UnB), Juan H. Moldau (USP), Werner Baer (Univ. de Illinois, E.U.A.).

COMISSĀO EDITORIAL: Atos Freitas Grawunder, Pedro Cezar Dutra Fonseca, Reinaldo Ignacio Adams e Roberto Camps Moraes.

EDITOR: Nali de Jesus de Souza

SECRETARIA: Maria Ivone de Mello (normalização), Vanete Ricacheski (revisão de textos), Zélide Bregalda (Secretária).

FUNDADOR: Prof. Antônio Carlos Santos Rosa

Os materiais publicados na revista Análise Econômica são de exclusiva responsabilidade dos autores. É permitida a reprodução total ou parcial dos trabalhos, desde que seja citada a fonte.

Aceita-se permuta com revistas congêneres. Aceitam-se, também, livros para divulgação, elaboração de resenhas ou recensōes.

Toda correspondência, material para publicação, assinaturas e permutas devem ser dirigidos ao seguinte destinatário:

PROF. NALI DE JESUS DE SOUZA

Revista Análise Econômica

Av. João Pessoa, 52

90.040 - PORTO ALEGRE (RS), BRASIL

Telefone: (0512) 25-58-44 ramal 33

Fax: (0512) 25-5253 


\title{
PREÇOS EXTERNOS E EXPORTAÇÃO DE \\ MANUFATURADOS: UM ESTUDO DOS PRINCIPAIS PRODUTOS*
}

\author{
Lauro Lobo Burle ${ }^{\star \star}$
}

\section{SINOPSE}

Este trabalho evidencia, para certos produtos manufaturados de exportação, a ocorrência simultånea de queda de preços e aumento de receitas, entre 1980 e 1985, indicando a atuação de outros fatores favoráveis, como a polftica cambial e os incentivos fiscais do BEFIEX. O autor conclui que $o$ aumento das receitas deu-se através de uma maior utilização de fatores produtivos internos, para um dado volume de divisas.

\section{INTRODUÇÃo}

O Brasil, na década de oitenta, conseguiu considerável avanço nas exportações de produtos manufaturados. O País que, até meados dos anos sessenta, exportava, sobretudo produtos agrícolas, passou, posteriormente, e basicamente na década de oitenta, a se constituir em notável exportador de produtos químicos, siderúrgicos, de autoveículos e acessórios e de uma série de outros produtos manufaturados.

Ao mesmo tempo, constatou-se que foi na primeira metade dos anos oitenta que ocorreu, também, uma generalizada queda dos preços das exportações, acontecimento que, por sinal, verificava-se desde o

* Este artigo e parte da dissertaçáo de mestrado apresentada pelo autor na Universidade de Brasnia e foi publicado nos Anais do Seminário sobre "A Inserção Internacional do Brasil nos Anos 90", realizado pelo CORECON-SP, entre 26 e 30 de março de 1990 . O autor agradece ao Professor Reinaldo Gonçalves da FEAVUFRJ pelos comentários durante a elaboração da dissertaçăo de mestrado.

** Professor do Centro Unificado de Brasflia e assessor económico da Confederação Nacional dos Trabalhadores nas Empresas de Crédito.

\begin{tabular}{|l|l|l|l|l|}
\hline ANÁLISE ECONO̊MICA & ANO 8 & N2 14 & NOVEMBRO/90 & p.39-49 \\
\hline
\end{tabular}


primeiro "choque" do petróleo, em 1974. Dentro desse cenário, objetivase, neste trabalho, focalizar este fenômeno da queda dos preços das exportações e concomitante aumento das receitas de grande parte dos produtos da pauia brasileira.

Para isso, na seção 2, apresentam-se as explicações teóricas para a deterioração dos preços relativos do comércio exterior de um pais; na seção 3, estuda-se a evolução dos preços em dólares e os preços relativos; na seção 4, efetua-se uma comparação do comportamento das exportações, no período de 1980-85, visando extrair as conclusões da seção 5.

\section{ARGUMENTOS PARA A DETERIORAÇÃO dOS PREÇOS RELATIVOS}

De acordo com o enfoque da "Deterioração das Relações de Troca"1, os preços dos produtos primários exportados pelos países periféricos (paises em desenvolvimento) tenderiam a cair relativamente aos preços dos produtos manufaturados exportados pelos paises centrais (paises desenvolvidos). Uma das explicações ${ }^{2}$ para esse fenômeno se basearia no comportamento cíclico da economia internacional (Rodrigues, 1981, p.63). As melhorias das relações de troca (preços relativos) para a periferia, registradas nas fases de dinamismo do crescimento, seriam mais do que anuladas pelas deteriorações que se verificariam nos momentos de diminuição do crescimento econômico. Como resultado final, no longo prazo, as relações de troca se deteriorariam para a periferia.

Argumenta-se que, nas fases de menor crescimento ou de recessão econômica como a década de 80 , as relações de troca se deteriorariam para a periferia em virtude de duas razões básicas: maior excedente de mão-de-obra e menor elasticidade-preço da oferta do setor primário-exportador da periferia, relativamente aos países centrais.

O maior excedente de mão-de-obra da periferia, dadas as altas taxas de produtividade do setor primário-exportador, faria com que, numa conjuntura recessiva, os salários tendessem a cair mais do que no centro. Por outro lado, a menor elasticidade-preço da oferta do setor primário da periferia resultaria na menor rapidez de adaptação à contraçáo da

1 Para os argumentos a serem apresentados, ver (Rodriguez, 1981) e (Michaely, 1984, p.137-40). 
demanda externa, em relação ao setor industrial-exportador do centro, levando à queda dos preços relativos.

Uma outra explicação ${ }^{2}$ para a deterioração das relações de troca se fundamentaria nas caracteristicas do desenvolvimento econômico da periferia. Este se daria na especialização no setor primário-exportador, em detrimento do setor industrial voltado para o mercado interno. Enquanto o setor primário se moderniza, o setor industrial permanece relativamente atrasado. Isso faria com que o fluxo de comércio se constituísse basicamente por bens primários na exportação e por bens industriais na importação. Dadas as diferenças estruturais assinaladas anteriormente, entre o setor industrial e o setor primário, o desenvolvimento econômico necessariamente levaria à queda dos preços relativos.

Apesar da teoria da "Deterioração das Relações de Troca" se referir a bens primários de exportação e produtos manufaturados de importação, ela se apresenta aplicável na avaliação dos preços relativos deste trabalho, já que existe diferença de composição de itens entre o produto brasileiro e o produto do país tomado como referência do preço mundial.

\section{ANÁLISE E AVALIAÇÃo dAS FLUTUAÇÕES NOS PREÇOS}

Foram selecionados 19 produtos manufaturados de acordo com a definição SITC (Standard International Trade Classification) a três dígitos das Nações Unidas ${ }^{3}$. Tomou-se uma amostra inicial de 25 produtos selecionada de acordo com o valor exportado em 1983 e excluiu-se aqueles que apresentaram elevação dos preços em dólares entre 1980 e 1985.

Com base em (Burle, 1988, p.33), as exportações dos 19 produtos selecionados totalizaram US\$ 6.201,4 milhões em 1985, representando quase $25 \%$ das exportações totais. Nesse ano os principais produtos em valor exportado foram autoveículos e acessórios (US\$1.351,9 milhōes) e produtos químicos orgânicos (US\$725,6 milhões), enquanto que os de menor importância foram motores e geradores elétricos (US\$ 84,9 miIhões) e outros artigos de tecidos (US $\$ 109,4$ milhões).

2 Rodriguez (1981, p.142-46).

3 Dentre os produtos desconsiderados destacam-se os de origem alimentícia, tais como farelo e torta de soja, preparaçōes de frutas, açúcar refinado e cristal, preparaçōes de carne ë manteiga de cacau (UNIONS NATIONS, 1983). 


\subsection{Evolução dos Preços em Dólares do Brasil}

Constata-se pela Tabela I que, entre 1980 e 1985, os índices de preços em dólares da maioria dos produtos considerados caíram, sendo de se destacar os casos de couro $(-54,6 \%)$; aço ou ferro ém lingotes $(-50,0 \%)$; materiais plásticos e resinas artificiais $(-43,1 \%)$; máquinas e componentes elétricos não-especificados $(-41,2 \%)$; papel e papelão $(-40,2 \%)$; ferro-gusa, ferro-ligas e ferro-esponja $(-39,1 \%)$; máquinas para indústria de papel, gráfica e alimentícia $(-30,6 \%)$; produtos quimicos orgânicos (-25,4\%); máquinas agrícolas $(-24,1 \%)$; e chapas de ferro ou de aço $(-22,5 \%)$.

Dos produtos acima, excluindo máquinas e componentes elétricos não-especificados; máquinas para indústria de papel, gráfica e alimenticia; e máquinas agrícolas, os demais refletiram a queda dos preços das "commodities" . No entanto, conforme se verá na seção IV, a queda dos preços foi mais do que anulada pelo aumento da quantidade exportada, pois as receitas da maioria dos produtos aumentaram no periodo.

No caso dos produtos químicos (produtos químicos orgânicos; materiais plásticos e resinas artificiais; e artefatos de borracha não-especificados), os preços em dólares já haviam se recuperado em 1988. Segundo o coordenador do Departamento do Comércio Exterior da Associação Brasileira da Indústria Química e Derivados (ABIQUIM), Walter Paul Krause ${ }^{5}$, os preços FOB em dólares convertidos pela taxa de câmbio estavam de 30 a $50 \%$ acima dos internos nesse ano, indicando que o setor apresentava boa rentabilidade relativa.

Também nos casos dos têxteis (fios e fibras têxteis; tecidos de algodão; e outros artigos de tecidos), a competitividade-preço não se encontrava ameaçada em 1988. Conforme apontava o LTCB of Japan/ IPEA (1988:175) ...."Estes artigos são competitivos internacionalmente em preço e qualidade".

Com relação às exportações de papel e papelão e produtos siderúrgicos, pode-se dizer que tais produtos foram atingidos pelo excesso de produção no mercado internacional, o que parece ter aberto oportunidade para países com grandes vantagens comparativas de custo com - Brasil, ocuparem espaço na demanda externa. (FUNCEX, 1984, p.77-78 e 101)

4 Conforme Rattner (1987, p.623), “... Essa queda abrange desde produtos alimenticios, óleos vegetais, matérias-primas agricolas, até minérios não-ferrosos e petróleo cru".

5 Contorme o Jornal Folha de Săo Paulo, 08 setembro 1988, p.H.5. 


\section{TABELA 1}

\section{INDICES DE PREÇOS EM DÓLARES DO BRASIL a DOS PRODUTOS SELECIONADOS - 1980/85}

\begin{tabular}{|c|c|c|c|c|c|c|}
\hline PRODUTOS & 1980 & 1981 & 1982 & 1983 & 1984 & 1985 \\
\hline Produtos químicos orgânicos & 100,0 & 110,1 & 86,2 & 75,9 & 69,9 & 74,6 \\
\hline $\begin{array}{l}\text { Materiais plásticos e resinas artifi- } \\
\text { ciais }\end{array}$ & 100,0 & 74,5 & 72,5 & 64,5 & 61,9 & 56,9 \\
\hline Couro & 100,0 & 63,3 & 46,4 & 36,5 & 55,9 & 45,4 \\
\hline Artefatos de borracha não-especifi- & & & & & & \\
\hline $\begin{array}{l}\text { cados } \\
\text { Papel e papelão }\end{array}$ & $\begin{array}{l}100,0 \\
100,0\end{array}$ & $\begin{array}{r}113,5 \\
80,9\end{array}$ & $\begin{array}{r}105,8 \\
79,9\end{array}$ & $\begin{array}{l}89,9 \\
60,7\end{array}$ & $\begin{array}{l}74,6 \\
61,3\end{array}$ & $\begin{array}{l}85,9 \\
59,8\end{array}$ \\
\hline Fios e fibras têxteis & 100,0 & 82,1 & 77,1 & 73,5 & 79,2 & 76,3 \\
\hline Tecidos de algodão & 100,0 & 87,1 & 83,4 & 77,4 & 78,5 & 77,6 \\
\hline Outros artigos de tecidos & 100,0 & 106,6 & 102,3 & 88,1 & 88,1 & 79,5 \\
\hline $\begin{array}{l}\text { Ferro-gusa, ferro-ligas e ferro-es- } \\
\text { ponja }\end{array}$ & 100,0 & 108,0 & 95,9 & 61,6 & 79,1 & 60,9 \\
\hline Aço ou ferro em lingotes & 100,0 & 66,4 & 58,5 & 46,8 & 50,9 & 50,0 \\
\hline Chapas de ferro ou de aço & 100,0 & 96,3 & 87,6 & 74,7 & 80,9 & 77,5 \\
\hline Tubos de ferro ou de aço & 100,0 & 127,1 & 130,9 & 79,1 & 81,0 & 87,7 \\
\hline Máquinas agrícolas & 100,0 & 114,3 & 106,9 & 81,3 & 120,6 & 75,9 \\
\hline $\begin{array}{l}\text { Máquinas para indústria de papel, } \\
\text { gráfica e alimentícia }\end{array}$ & 100,0 & 102,9 & 126,6 & 103,2 & 71,6 & 69,4 \\
\hline Måquinas não-especificadas & 100,0 & 110,9 & 117,9 & 119,3 & 94,6 & 84,5 \\
\hline Motores è geradores elétricos & 100,0 & 112,5 & 124,3 & 110,7 & 78,3 & 79,4 \\
\hline $\begin{array}{l}\text { Máquinas elétricas não-especifica- } \\
\text { das }\end{array}$ & 100,0 & 82,0 & 132,9 & 116,6 & 66,9 & 58,8 \\
\hline Autovefculos e acessórios & 100,0 & 110,6 & 125,8 & 117,4 & 97,9 & 97,4 \\
\hline Vestuário (exclusivo de couro) & 100,0 & 97,8 & 105,6 & 85,6 & 90,4 & 89,7 \\
\hline
\end{tabular}

FONTE: UNIONS NATIONS (1983)

NOTA: a) Anos de 1984 e 1985 originalmente obtido da CACEX convertidos para a SITC através da compatibilizaçăo com a NBM (UNIONS NATIONS, 1974)

Em síntese, verifica-se que a queda dos preços da maioria dos produtos na primeira metade dos anos 80 , refletindo a retração da economia e do comércio munidiais em 1982, além de ser neutralizada por 
outros fatores, parece ter sido revertida a partir de 1985 para os produtos enfocados 6

\subsection{Evolução dos Preços-Relativos}

Os preços relativos por produto foram obtidos através do quociente entre os índices de preços em dólares brasileiros (tabela l) e os índices de preços em dólares mundiais, os quais se referem aos principais exportadores de manufaturados, tais como, Estados Unidos, Japão, Alemanha Ocidental e Reino Unido (Burle, 1988, p.80).

De acordo com a seção II, em fases recessivas da economia internacional os preços relativos se deteriorariam para um pais periférico como o Brasil, já que os produtos (ou itens) exportados por este país tendem a apresentar uma menor elasticidade-preço da oferta e um comportamento dos preços mais flexivel para baixo - dado o excedente de mão-de-obra existente no mercado de trabalho - do que os países centrais.

Pela tabela II, verifica-se que as principais quedas de preços relativos entre 1980 e 1985 ocorreram com couro (-39,3\%); máquinas e componentes elétricos não-especificados $(-38,7 \%)$; aço ou ferro em lingotes $(-29,64 \%)$; ferro-gusa, ferro-ligas e ferro-esponja $(-26,1 \%)$; e materiais plásticos e resinas artificiais $(-25,1 \%)$.

Além disso, considerando o periodo pós-primeiro "choque" do petróleo ou seja, 1974/85, dos 19 produtos considerados, 11 apresentaram queda dos preços relativos a um nível de confiança de $5 \%$, sendo que dos oito restantes, somente dois apresentaram sinal positivo no coeficiente de correlação de ordem de Spearman (Burle, 1988, p.92).

Os produtos que apresentaram queda dos preços relativos a um nivel de confiança satisfatório foram: produtos químicos orgânicos; materiais plásticos e resinas artificiais; couro; fios e fibras têxteis; ferro ou aço em lingotes; chapas de ferro ou de aço; máquinas para indústria de papel, gráfica e alimentícia; máquinas mecânicas não-especificadas; motores e geradores elétricos; máquinas elétricas não-especificadas e vestuário (exclusive de couro). Por outro lado, os produtos que apresentaram elevação dos preços relativos foram papel e papelão e autoveiculos e acessórios (lbid, p.93).

6 Segundo dados da CACEX (Banco Central, 1988, p.425-43) pode-se dizer que, com exceção de alguns bens de capital (p.e., motores e geradores elétricos), todos demais produtos considerados apresentaram elevação dos preços em dólares entre 1985 e agosto de 1988. 
Conclui-se, assim, que o fenômeno da queda dos preços externos dos produtos considerados atingiu mais o Brasil do que os paises desenvolvidos exportadores de manufaturados. Isso mostra que, para se obter um mesmo volume de divisas, o País teve que gastar mais fatores produtivos relativamente, ou que se empobreceu frente aos paises industrializados na primeira metade dos anos 80 .

TABELA 2

ÍNDICES DE PREÇOS RELATIVOS DOS PRODUTOS SELECIONADOS - 1980/85

(1980: 100)

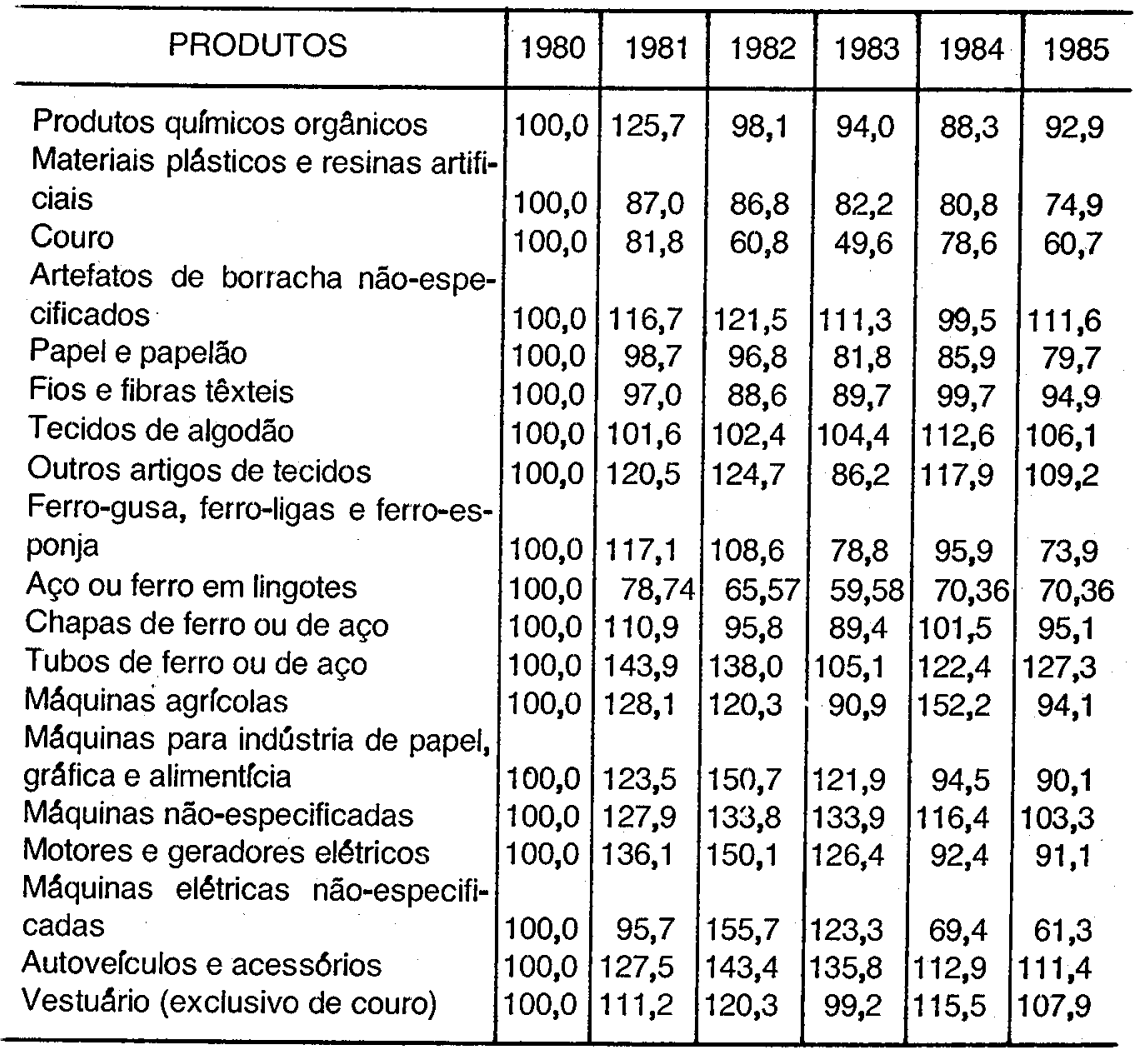

FONTE: Tabela 1 e Burle (1988).

NOTA: a) Para o método de obtenção dos preços em đólares mundiais utilizados na estimativa dos preços relativos, ver (Burle, 1988, p. 80). 


\section{COMPARAÇÃO COM AS RECEITAS DAS EXPORTAÇÕES}

No quadrante esquerdo da tabela III, verifica-se que, para cinco produtos - máquinas agrícolas; máquinas para indústria de papel, gráfjca e alimentícia; máquinas mecânicas não-especificadas; mótores e geradores elétricos; e máquinas elétricas não-especificadas -, os preços em dólares cairam juntamente com as exportaçōes.

No caso de máquinas agrícolas, a retração das vendas externas parece ter sido provocada pelo dinamismo alcançado pelo setor agrícola nos anos 1984/85. No caso dos demais bens de capital, pode-se dizer que são produtos que o Brasil parece ainda não atingir uma escala produtiva competitiva internacionalmente, ainda mais num contexto de politica econômica recessiva tal como, o triênio 1981/83'.

Por outro lado, no quadrante direito encontra-se nada menos do que 14 produtos, isto é, aqueles que tiveram preços externos reduzidos e aumento das exportações. Se isso ocorreu, é porque outros fatores internos e/ou externos anularam o efeito da queda dos preços.

Para os casos de produtos químicos orgânicos; materiais plásticos e resinas artificiais; artigos de borracha não-especificados; papel e papelão; ferro-gusa, ferro-ligas e ferro-esponja; aço ou ferro em lingotes; chapas de ferro ou de aço; e tubos de ferro ou de aço pode-se destacar o programa de substituição de importações do II PND (Plano Nacional de Desenvolvimento) (Castro, 1985, p.86).

Para os casos dos produtos têxteis, principalmente as manufaturas e tecidos de algodão, as exportações aumentaram em virtude dos baixos custos de produção e do alto padrão de qualidade atingido.

Com relação as exportações de autoveículos e acessórios, as receitas parecem ter sido incrementadas pelo desaquecimento do mercado interno e, principalmente, pelos incentivos fiscais recebidos através do programa BEFIEX (Biato, 1984, pp.182-187).

Entretanto, conforme visto na seção 2, mesmo com o aumento das receitas das exportações, a deterioração dos preços relativos constatada representou maior montante de recursos internos, em termos de insumos produtivos utilizados, transferidos para o exterior em troca de um dado volume de divisas, ou seja, uma apropriação de renda pelos mercados importadores.

7 Sobre a competitividade-preço de tais produtos, ver Araújo (1982). 


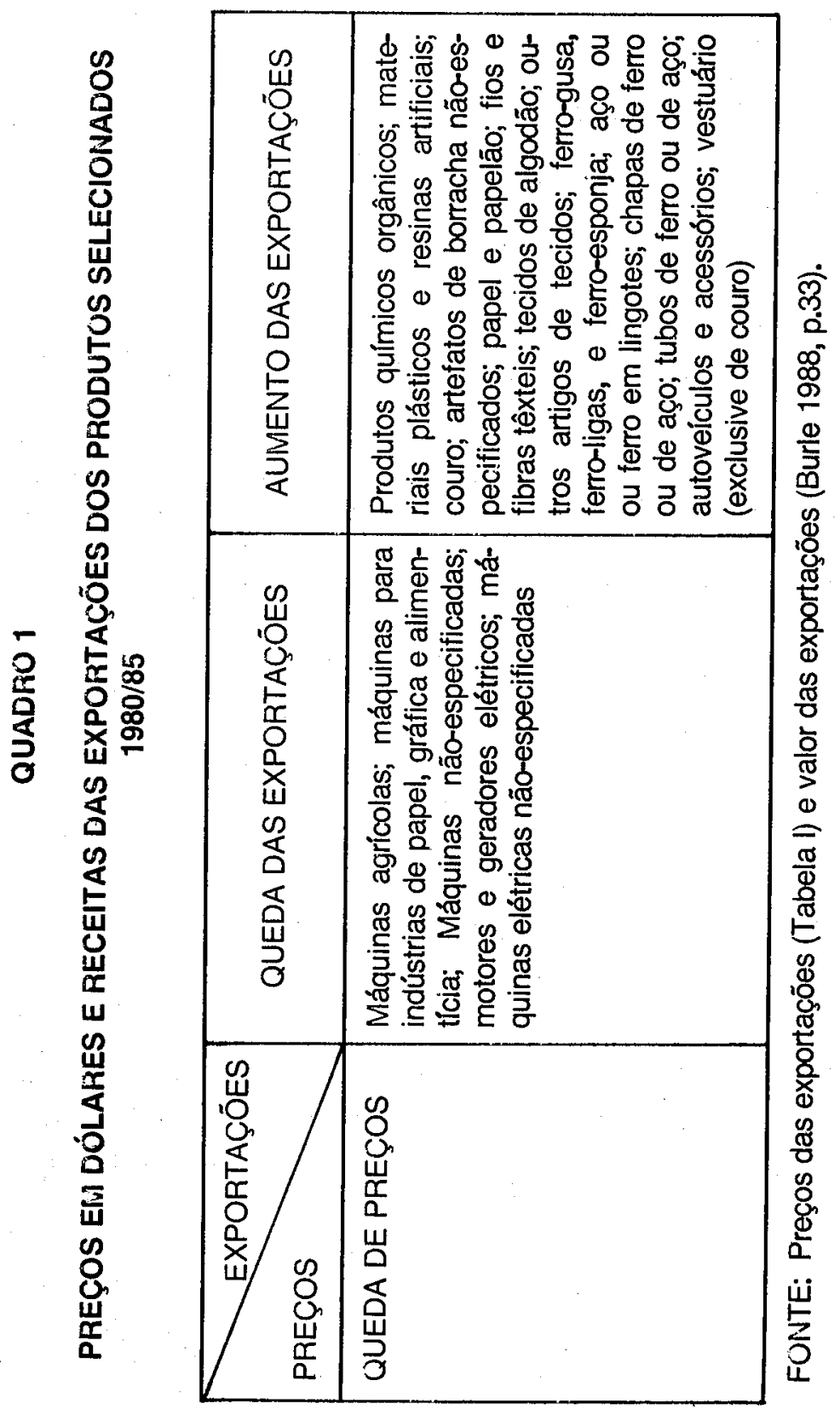


Entre 1980 e 1985 houve queda dos preços relativos e aumento das exportações para produtos químicos orgânicos; materiais plásticos e resinas artificiais; couro; papel e papelão; fios e fibras têxteis; ferro-gusa, ferro-ligas e ferro-esponja; aço ou ferro em lingotes; e chapas de ferro ou de aço, ou seja, todos intensivos em recursos naturais (tabela 2 e quadro 1).

\section{CONCLUSÕES}

Este trabalo terá alcançado seu objetivo se tiver levado ao leitor informação adicional sobre o período atípico do comércio exterior brasileiro, que foi a primeira metade dos anos 80 . Se, por um lado, o País alcançou altos saldos comerciais, por outro lado, registrou uma acentuada deterioração dos preços em dólares das exportaçōes.

Embora o artigo não permita inferir conclusões precisas sobre cada produto, pode-se dizer que, no global, a pauta de manufaturados considerada foi atingida por diversos fatores incrementadores da rentabilidade das vendas externas, tais como a política cambial agressiva do triênio 1983/85, a manutenção dos incentivos fiscais do BEFIEX, a maturação dos investimentos do II PND, o dinamismo da economia americana e o desaquecimento do mercado interno.

Ao mesmo tempo, na primeira metade da década de 80 e dentro do conjunto de produtos considerados, o Brasil parece ter aumentado as receitas das exportações tendo que utilizar mais fatores produtivos internos relativamente aos países industrializados. Ou seja, houve uma transferência de renda para o exterior, na forma de redução real dos salários e dos preços dos recursos naturais existentes.

As perspectivas para os anos 90 são que, para preservar os mercados externos arduamente conquistados, o País terá que adotar políticas de incentivo que mantenham a competitividade das exportaçōes. Ao lado disso, será essencial se retomar o investimento em tecnologia e, assim, aumentar a qualidade e o valor unitário dos produtos brasileiros relativamente aos concorrentes externos.

\section{BIBLIOGRAFIA}

ARAÚJO JÚNIOR, J.T. Mudança Tecnológica e Competitividade das Exportações Brasileiras de Manufaturados. Rio de Janeiro, IEl/ UFRJ, 1982. (Texto Para Discussão, n.8). 
BANCO CENTRAL DO BRASIL. Boletim Mensal, v.24, n.9, set. 1988. BIATO, Márcia F. Programa de Incentivo às Exportaçōes: Estudo de Caso do BEFIEX. Brasília, 1984. (Dissert. mestrado econ.), UNB.

BURLE, Lauro L. Fatores de Risco na Competitividade das Exportações Brasileiras de Manufaturados. Brasília, 1988. (Dissert. mestrado econ.), UNB.

CASTRO, Antônio B. \& SOUZA, F.E.P. A Economia Brasileira em Marcha Forçada. Rio de Janeiro, Paz e Terra, 1985.

FOLHA DE SÃO PAULO, 8 setembro 1980, p.H5.

FUNCEX. Desempenho do Comércio Exterior Brasileiro, 1984.

LTCB/IPEA. Current Brazilian Economy and Business Opportunities.

Part Two: The Long-Term Credit of Japan Ltda., Jun. 1988, p.143-80.

MICHAELY, M. Trade, Incorne Levels, and Dependence. North Holand,

Studies in International Economics, v.8, 1984, p.137-40.

RATTNER, Henrique. Por uma Política Industrial Alternativa. In. ENCONTRO NACIONAL DE ECONOMIA, 15, Brasília, 1987. Anais... São Paulo, ANPEC, 1987. v.2, p.609-35.

RODRIGUES, Octávio. Teoria do Subdesenvolvimento da CEPAL. Rio de Janeiro, Forense, 1981.

UNIONS NATIONS. Commodity Trade Statistics. Série D, Brasil, 1983. . Standard International Trade Classification. Rev. 2, série $\mathrm{M}, 1974$.

\section{ABSTRACT \\ EXTERNAL PRICES AND THE EXPORT OF MANUFACTURES: A STUDY OF THE MAIN GOODS}

This study shows that, for some export manufactures, there is a simultaneous incidence of decrease in prices and increase in revenues between 1980 and 1985, indicating the influence of other favorable factors, such as the foreign exchange policy and the fiscal benefits of BEFIEX. The author concludes that the revenue increase is due to a larger utilization of the domestic productive factors, for a given level of foreign currencies. 